\title{
The development of a road safety management model
}

\author{
D. O'Cinneide \& L. Harrington \\ Traffic Research Unit, University College Cork, Ireland
}

\begin{abstract}
This paper proposes that road safety investment can be optimised by the development of a road safety management model. Road safety strategies typically include a basket of engineering, enforcement and education/training measures but there does not appear to be any management model which permits the optimisation of road safety investment. The proposed model utilises linear programming to predict changes in road safety resulting from safety interventions. It is mainly based on research in the areas of engineering and enforcement since there is little published research on the correlation between education and accident reduction. The model output provides the accident reduction and associated costs resulting from feasible road safety strategies. This should benefit policy makers when allocating resources.
\end{abstract}

Keywords: road safety management model, road safety policy, performance indicators, linear programming.

\section{Introduction}

The three countries with the safest roads in Europe, Sweden, the United Kingdom and the Netherlands, implement comprehensive road safety strategies that involve local authorities, road users, emergency services, enforcement agencies, etc. Such strategies require a management system to optimise road safety levels. This paper proposes a linear programming technique to assist in the optimisation of resources.

Safety countermeasures that could be implemented in a road safety strategy are first examined. The selection of safety performance indicators is then discussed. Both safety countermeasures and performance indicators are then 
used in a linear programming model. The model estimates the likely outputs from safety interventions in terms of accident reductions subject to constraints such as maximum feasible enforcement levels.

\section{Road safety countermeasures}

The three main approaches normally applied in road safety management are engineering, enforcement and education. It is considered that the success of road safety campaigns is increased through the implementation of countermeasures from all three approaches [1].

\subsection{Engineering countermeasures}

Engineering road safety interventions primarily relate to measures that involve the treatment of the roadway. These vary from new warning signs to road realignment or the installation of traffic calming schemes. The majority of Ireland's road network comprises of undivided two lane roads. This type of road presents the greatest accident risk to motorists; a recent study has shown that the fatal accident rate on undivided roads in Ireland is 9 times that on motorways [2]. Obviously it is not possible to upgrade all roads to motorways but there are many other engineering safety measures available. For example, if a considerable number of accidents involve vulnerable road users, traffic calming measures which reduce vehicle speeds and provide additional footways may be appropriate. A 'before and after' study of traffic calming schemes on Irish interurban routes found that the average accident rate reduced from 8 accidents per annum to 3.5 accidents per annum [3]. Typical accident reductions resulting from engineering measures are shown in Table 1.

Table 1: $\quad$ Typical reductions in accidents from engineering measures [4].

\begin{tabular}{|l|l|}
\hline Countermeasure & $\%$ accident reduction \\
\hline Installation of general warning signs & 25 \\
\hline Upgrading of roadway delineation & 15 \\
\hline Installation of no passing zone through delineation & 40 \\
\hline Lighting of at grade intersections (overall) & 30 \\
\hline Lighting of at grade intersections (night) & 50 \\
\hline Installation of right-turning lanes & 35 \\
\hline Installation of rumble strips & 25 \\
\hline Improvement of road surface & 25 \\
\hline Installation of crash barrier (fatal accidents) & 65 \\
\hline Sight distance improvements & 30 \\
\hline Improvement of horizontal alignment & 40 \\
\hline Construct grade-separated interchange & 55 \\
\hline
\end{tabular}




\subsection{Enforcement countermeasures}

Enforcement has been shown to significantly reduce traffic accidents. Research in Ireland indicates that a $1 \%$ increase in the number of hours spent on police surveillance could yield a $2.6 \%$ reduction in the number of serious injury accidents [5]. The European Transit Safety Council estimates that 50\% of traffic accidents could be avoided if road users complied completely with road traffic regulations [1]. If traffic violations were eliminated, it has been estimated that fatalities could be reduced by as much as $63 \%$ [6]. Three specific violations contribute considerably to accident fatalities, speeding, drink driving and seat belt use [7].

Excessive speed is by far the most prevalent traffic offence [1]. A considerable reduction in fatalities resulted from the introduction of penalty points for speeding in Ireland in late 2002. Unfortunately, this effect has since diminished due to a lack of enforcement. A number of studies have investigated the impact of enforcement on traffic accidents including the use of fixed and mobile speed cameras. Table 2 summarises the researched effects of both manual and automated speed enforcement.

Table 2: $\quad$ Effects of manual and automatic speed enforcement.

\begin{tabular}{|l|l|l|}
\hline Effect & $\begin{array}{l}\text { Manual } \\
\text { enforcement }\end{array}$ & $\begin{array}{l}\text { Automatic } \\
\text { enforcement }\end{array}$ \\
\hline \% Reduction in accident frequency & $2-4$ & $20-24$ \\
\hline \% Reduction in no. KSI ${ }^{*}$ accidents & $14-58$ & $17-38$ \\
\hline \% Reduction in mean speed & $3.6-4.5$ & 4 \\
\hline Average speed reduction $(\mathrm{km} / \mathrm{h})$ & 3.6 & $2.9-6.9$ \\
\hline Distance halo $(\mathrm{km})$ & $1.6-3.5$ & $1-10$ \\
\hline Time halo (days) & $1-63$ & not applicable \\
\hline
\end{tabular}

*KSI $=$ Killed and Seriously Injured.

Driving under the influence of alcohol increases the likelihood of being involved in traffic accidents. The chances of detection while driving in excess of the legal blood alcohol limit in Ireland is estimated as 1 in 300, which is considerably lower than in the United Kingdom (1 in 65) and lower still than in the Netherlands ( 1 in 20) or Sweden or (1 in 9) [8]. The European Commission recommends that random breath testing (RBT) should be adopted by all member states to deter drivers from drinking so that every driver has a probability of being tested at least once every three years [9]. Random breath testing was implemented in Ireland in mid 2006. In a meta-analysis based on a total of 39 studies Elvik [7] found that the overall effects of enforcing drink driving regulations were reductions of $9 \%$ and $7 \%$ in the number of fatal and injury accidents respectively. These reductions were statistically significant.

It is widely accepted that wearing seat belts reduce the severity of traffic accident injuries. Seat belts are estimated to reduce the likelihood of being killed in a collision by as much as $60 \%$ [8]. In an analysis of fourteen seat belt 
enforcement studies, Elvik [7] found that the best estimate of the effect of seat belt enforcement on the number of fatal accidents was a $6 \%$ reduction and an $8 \%$ reduction in the number of injury accidents.

\subsection{Education countermeasures}

Education including driver training is considered an essential component of road safety management and advertising forms part of most road safety campaigns. However, it has proved difficult to apportion accident reduction figures to education countermeasures.

\section{Road safety performance indicators}

Road safety can be assessed in terms of accident frequency and resultant costs but simply counting crashes or injuries can produce an imperfect indication of the level of road safety. For example, the under reporting of traffic accidents, as high as $50 \%$ for minor accidents and $25 \%$ for serious injury accidents in Ireland [2], can produce an apparent change in the number of reported accidents.

Accident counts need to be supplemented by other measurements that are causally related to crashes or injuries in order to indicate performance [10]. These additional measurements are referred to as safety performance indicators. Regular monitoring of such performance indicators can improve the understanding of road accident trends by providing a more complete picture of the level of road safety and by pointing to the emergence of new problems at an early stage. Some EU member states have shown that safety performance indicators can be used efficiently for monitoring the progress of road safety policies in meeting their desired targets and for permitting interventions where necessary [10]. The most commonly used safety performance indicators for road transport in Europe include speed measurement, seat belt and crash helmet usage and drink driving incidence.

Table 3 suggests performance indicators for the evaluation of Irish road safety. It should be noted that these performance indicators require further refinement.

\section{Linear programming model}

One of the central components of the road safety management process is the allocation of resources. It is suggested that linear programming can be used to optimise the road safety countermeasures. The objective of this model is to provide a system of road safety management whereby different road safety measures/strategies (inputs) are analysed and the resultant effects (outputs) are quantitatively estimated.

\subsection{Scope of the model}

The safety situation on a specific route is first quantified. The level of safety achieved through the implementation of selected engineering and/or enforcement 
road safety interventions is then estimated. The output generated by the model represents the expected magnitude of road safety in terms of accident severity and cost. Ideally, the model should also indicate if the proposed road safety measures are cost effective.

\subsection{Formulation of the model}

The model operates on the basis of estimating the effectiveness of the selected input variables (road safety measures). The effectiveness estimation apportions the expected accident reduction benefits to the road safety measures. These benefits are correlated with performance indicators so that outputs can be produced in relation to different road users and/or road categories.

Table 3: $\quad$ Suggested safety performance indicators for Ireland.

\begin{tabular}{|c|c|c|}
\hline Category & Subject & Indicator \\
\hline \multirow[t]{2}{*}{$\begin{array}{l}\text { Primary } \\
\text { indicator }\end{array}$} & Distance travelled & $\begin{array}{l}\text { Accidents/million vehicle kilometres of } \\
\text { travel }\end{array}$ \\
\hline & Fatality rate & Accident fatalities $/ 100,000$ population \\
\hline \multirow[t]{4}{*}{ Behaviour } & Speed & $\begin{array}{l}\text { \% cars above legal limit } \\
\% \text { HGV's above legal limit } \\
\text { Standard deviation } \\
85^{\text {th }} \text { percentile }\end{array}$ \\
\hline & Alcohol & $\begin{array}{l}\% \text { accidents between } 21: 00 \text { and } 03: 00 \\
\% \text { above legal limit }\end{array}$ \\
\hline & Seat belts & $\%$ car occupants using seat belts \\
\hline & Enforcement & No. of surveillance hours \\
\hline \multirow[t]{2}{*}{ Vehicles } & Primary safety & $\begin{array}{l}\text { \% compliance with headlight and tyre } \\
\text { tread depths }\end{array}$ \\
\hline & Secondary safety & $\%$ cars achieving Euro-NCAP standards \\
\hline Road & $\begin{array}{l}\text { Road design and } \\
\text { construction } \\
\text { quality }\end{array}$ & $\begin{array}{l}\% \text { road network achieving Euro-RAP } \\
\text { standards } \\
\% \text { motorways, dual carriageways and } \\
2+1 \text { roads } \\
\% \text { network safety audited } \\
\text { No. of high accident locations }\end{array}$ \\
\hline \multirow[t]{3}{*}{$\begin{array}{l}\text { Vulnerable } \\
\text { road users }\end{array}$} & $\begin{array}{l}\text { Road } \\
\text { construction }\end{array}$ & No. of traffic calming schemes \\
\hline & Speed & \% motorcyclists above legal limit \\
\hline & Drivers & $\begin{array}{l}\% \text { learner drivers; } \\
\% \text { drivers under } 25 \\
\% \text { foreign drivers }\end{array}$ \\
\hline $\begin{array}{l}\text { Trauma } \\
\text { management }\end{array}$ & Arrival time & $\%$ achieving response times \\
\hline
\end{tabular}


A linear programme typically consists of two parts, an objective function and constraints. The objective function is an equation that defines the quantity to be optimised. In the case of road safety management, linear programming is used to maximise the average cost saved by preventing road traffic accidents (objective function) subject to the implementation costs, geometrical constraints imposed by the road and resource constraints.

The hypothesis is that a linear programme can represent the magnitude of the road safety situation by defining the effects of the implemented road safety measures. In combining the effects of different road safety measures and their corresponding constraints, a representation (model) of the level of road safety may be attained.

Linear programming assumes that a problem can be approximated by linear functions. Therefore, the objective function and the constraints are assumed to be linear. Since the real situation seldom corresponds exactly with the model due to uncertainties and assumptions, sensitivity analysis of the optimal solution can indicate the quantitative effects of changing the constraints. Thus, the constraints which have the greatest effect on the optimisation of the objective function (minimising the cost of road traffic accidents) can be identified.

\subsection{Implementation of model}

As a simple illustrative example, the model is implemented on a section of the N22 National Primary Route between Ballincollig and Macroom, Co. Cork, Ireland. The main target set by Ireland's current road safety strategy is to reduce the number of road accident fatalities by $25 \%$ relative to the average number of fatalities recorded in the 1998-2003 period [11]. Therefore a reduction of at least $25 \%$ would be required on this section of the N22.

The objective function for the linear programming model is to minimise the cost of road accidents on the N22. It is now necessary to formulate a quantitative expression for the objective function. In this example two costs (decision variables) are proposed for inclusion in the objective function, these are:

1. The average cost saved by preventing one injury accident.

2. The average cost saved by preventing one fatal accident.

The average cost of a serious injury accident in Ireland is estimated as $€ 304,600$ whilst the average cost of a fatal accident is $€ 2,280,000$ [12].

If $\mathrm{X} 1$ represents the number of serious injury accidents prevented by the road safety measures and X2 represent the number of fatal accidents prevented, then the objective function can be written in terms of cost per accident as:

$$
304,600 X 1+2,280,000 X 2
$$

Speed is probably the single most influential factor affecting road traffic accidents. Therefore mean speed reduction is included as a decision variable in the objective function. It is assumed that the mean 'free flow' speed of vehicles on the route will be primarily reduced through enforcement. 
Based on the relationship developed by Engdahl and Nilsson [13], if the current level of direct enforcement on the route is trebled, the number of accidents would be expected to reduce by almost $12 \%$. This three times increase in the level of enforcement is assumed to be the maximum feasible increase (an enforcement constraint).

Finch et al [14] reported that a 5\% reduction in injury accidents is associated with every $1 \mathrm{mph}$ reduction in mean traffic speed. Therefore, to reduce the accident rate by $25 \%$, the mean speed would have to be reduced by $16 \mathrm{~km} / \mathrm{h}$. It is considered unlikely that this speed reduction would be achievable. An achievable mean speed reduction for the route is assumed to be $5 \mathrm{~km} / \mathrm{h}$. This is estimated to reduce the accident rate by $17 \%$. However, as shown above, a $12 \%$ reduction is the maximum achievable by direct enforcement. For this simple example, it is assumed that advertising will supplement the speed enforcement to achieve a $17 \%$ reduction in the accident rate through mean speed reduction.

The improvement of junctions/accesses along the route is also considered an appropriate method of improving the level of road safety since $46 \%$ of all fatal and injury accidents recorded on this road section occurred at such locations. Junction / access treatment is expected to result in the additional $8 \%$ required to meet the $25 \%$ accident reduction target.

Table 4 shows an estimate of the percentage change in the two safety measures (speed reduction and junction improvement) required to prevent one accident by type occurring on this section of the N22. Also shown in Table 4 is an estimate of the maximum level that each measure could feasibly contribute to the number of accidents prevented.

Table 4: Change in safety measures required per unit accident reduction.

\begin{tabular}{|l|l|l|}
\hline Objective goal & $\begin{array}{l}\% \text { mean speed } \\
\text { reduction }\end{array}$ & $\%$ junctions improved \\
\hline $\begin{array}{l}\text { One serious injury accident } \\
\text { prevented }\end{array}$ & 0.75 & 2.50 \\
\hline One fatal accident prevented & 6.50 & 5.00 \\
\hline Max. attainable & 25 & 50 \\
\hline
\end{tabular}

From the above table, the constraint expressions may be written as follows:

$$
\begin{gathered}
0.75 X 1+6.50 X 2 \leq 25 \\
2.50 X 1+5.00 X 2 \leq 50 \\
X 1 \geq 0 \\
X 2 \geq 0
\end{gathered}
$$

where $\mathrm{X} 1=$ Number of serious injury accidents prevented

$\mathrm{X} 2=$ Number of fatal accidents prevented

To summarise the linear programme, we now require values for $\mathrm{X} 1$ and $\mathrm{X} 2$ which will maximise $304,600 X 1+2,280,000 X 2$ and also satisfy the constraints. 
The above expressions can be plotted on a linear graph. All the points (X1, $\mathrm{X} 2$ ) that satisfy the constraints define what is known as the 'feasible region'. In linear programming the optimal solution is always found at a vertex of the feasible region. In this example there are three vertices satisfying this criteria. However, the optimum values for X1 and X2 are 16.0 and 2.0 respectively. Substituting the X1 and X2 values (maximum savings) into the objective function yields:

$$
304600(16.0)+2280000(2.0)=9433600
$$

Hence, it can be estimated from the objective function that if the optimum level of speed reduction and junction treatment is implemented, a gross economic saving of $€ 9433600$ can be attained. The cost of implementing these measures would have to be taken into account when undertaking a cost benefit analysis.

The above problem may also be formulated mathematically, expressed in terms of a simplex algorithm. Firstly, all constraints must be written as inequalities:

$$
\begin{aligned}
& =>0.75 X 1+6.50 X 2+S 1=25 \\
& =>2.50 X 1+5.00 X 2+S 2=50
\end{aligned}
$$

The variables $S 1$ and $S 2$ are used to rewrite the constraints, as inequalities. These new variables are therefore termed slack variables. Hence, the linear programming problem now has four variables. The algebraic steps of the simplex method can be organised into a systematic procedure in which a series of tables represent the information on each basic solution. The initial basic feasible solution for the linear programming problem is set out as follows in Table 5.

Table 5: $\quad$ Initial simplex table.

\begin{tabular}{|c|c|c|c|c|c|c|}
\hline $\mathrm{C}_{\mathrm{i}}$ & Basic Vars. & Cur. Sol. & $\mathrm{X} 1$ & $\mathrm{X} 2$ & $\mathrm{~S} 1$ & $\mathrm{~S} 2$ \\
\hline 0 & $\mathrm{~S} 1$ & 25 & 0.75 & 6.50 & 1 & 0 \\
\hline 0 & $\mathrm{~S} 2$ & 50 & 2.50 & 5.00 & 0 & 1 \\
\hline \multicolumn{2}{r|}{$\begin{array}{c}\text { Evaluation } \\
\text { Row }\end{array}$} & 0 & $304.6 \times 10^{3}$ & $2,280 \times 10^{3}$ & 0 & 0 \\
\hline
\end{tabular}

Thus there are zero entries in the evaluation row under S1 and S2 and nonzero entries under $\mathrm{X} 1$ and $\mathrm{X} 2$. If all the entries in the evaluation row were $\leq 0$, this would imply that the optimal solution has been attained, as any increase in the value of a non-basic variable could not increase the objective function.

This initial basic feasible solution does not correspond to the optimal solution. Therefore, to progress to the next vertex it is necessary to rewrite the constraints so that the new basic feasible solution may be evaluated. This is carried out by picking the most positive entry in the evaluation row that identifies the entering variable. The entering variable highlights what is referred to as the "pivot column'. It can be seen from Table 5 that column X2 is the pivot column. 
To determine the upper limit for $\mathrm{X} 2$ the minimum ratio is selected between the positive entries in the pivot column and the entries in the current solution column. From Table 5 it can be seen that $25 / 6.5$ provides the minimum ratio. This minimum ratio identifies the departing variable, i.e. S1. The row with the minimum ratio is termed the 'pivot row'. The number common to both the pivot column and pivot row is known as the 'pivot element', circled in Table 5.

The new basic feasible solution will have the basic variables X2 and S2, with the non-basic variables X1 and S1. To determine the new value for S1 and to rewrite the constraints so that the new basic feasible solution may be evaluated a numerical procedure known as a 'simplex transformation' must be undertaken, i.e. $a^{\prime}{ }_{i j}=a_{i j}-\left(a_{i l} a_{k j}\right) / a_{k l}\{$ for $i \neq k$ and all $j\}$

where

$\mathrm{a}_{\mathrm{ij}}$ and $\mathrm{a}_{\mathrm{ij}} \quad=$ Entries in the new and previous simplex tables respectively. $\mathrm{a}_{\mathrm{kl}}$ $=$ Pivot element

Table 6 presents the final simplex transformation table.

Table 6: Third simplex table (second transformation iteration) - optimal.

\begin{tabular}{|c|c|c|c|c|c|c|}
\hline $\mathrm{C}_{\mathrm{i}}$ & Basic Vars. & Cur. Sol. & $\mathrm{X} 1$ & $\mathrm{X} 2$ & S1 & $\mathrm{S} 2$ \\
\hline $2,280 \times 10^{3}$ & $\mathrm{X} 2$ & 2.0 & 0 & 0 & 0.20 & 0 \\
\hline $304.6 \times 10^{3}$ & $\mathrm{X} 1$ & 16.0 & 1.1 & 0 & 0 & 0 \\
\hline & $\begin{array}{l}\text { Evaluation } \\
\text { Row }\end{array}$ & $9,433 \times 10^{6}$ & 0 & 0 & $-350.8 \times 10^{3}$ & 0 \\
\hline
\end{tabular}

\section{Discussion and conclusion}

The above simple example was selected to illustrate the use of linear programming as a road safety management tool. Rather general assumptions were made regarding the effectiveness of the road safety countermeasures and the costs of the countermeasures were omitted. The simplex linear programming method was also used to determine the optimum combination of interventions, which can be expanded to include for further safety interventions.

Sensitivity analysis can also be carried out to investigate the implications of increasing the level of countermeasure implementation.

In conclusion, the proposed linear programming approach allows different road safety measures to be combined and their collective effect to be examined. This should be very useful in getting the best return from road safety resources.

\section{References}

[1] ETSC. Police Enforcement Strategies to Reduce Traffic Casualties in Europe, European Transport Safety Council, Brussels, 1999. 
[2] O'Cinneide, D., Murphy, J., Ryan, T. The Effect of Geometric Elements on Interurban Accident Rates, Procs. Transportation Research Board $3^{\text {rd }}$ International Symposium on Highway Geometric Design, Chicago.2005

[3] Harrington, L. Traffic Calming on Inter-Urban Road", MEngSc thesis, University College Cork. 2000

[4] Kentucky Transportation Centre, Development of Accident Reduction Factors, University of Kentucky. 1996

[5] Fuller, R., Farrell, E. Operation Lifesaver Assessment, RS 456, National Roads Authority, Dublin. 2001

[6] Elvic, R. Amundsen, A. H. Improving Road Safety in Sweden, Institute of Transport Economics, Oslo. 2000

[7] Elvik, R. Vegtrafikklovgivning, Kontroll og Sanksjoner. Potensialet for a bedre trafikksikkerheten og nytte-kostnadsvurdering av ulike tiltak, Transportation Institute, Oslo. 1997

[8] Wegman, F. Review of Ireland's Road Safety Strategy, SWOV, Leidschendam. 2002

[9] European Commission. COMMISSION RECOMMENDATION of 17 January 2001 on the maximum permitted blood alcohol content (BAC) for drivers of motorised vehicles, (2001/115/EC). 2001

[10] ETSC. Transport Safety Performance Indicators, European Transport Safety Council, Brussels. 2001

[11] Department of Transport. Road Safety Strategy 2004 - 2006, Department of Transport, Dublin. 2004

[12] Goodbody Economic Consultants. Cost Benefit Parameters and Application Rules for Transport Project Appraisal. Gooodbody Economic Consultants in Association with Atkins, Dublin. 2004

[13] Engdahl, S, Nilsson, E. Cited in ESCAPE Working Paper 1, Cost Benefit Analysis of Police Enforcement, (author Elvic, R.), Technical Research Centre of Finland (VTT), 2001

[14] Finch, D. J., Kompfiner, P., Lockwood, C. R., Maycock, G. Speed, Speed Limits and Accidents, Project Report 58, Transport Research Laboratory, Crowthorne, 1994. 